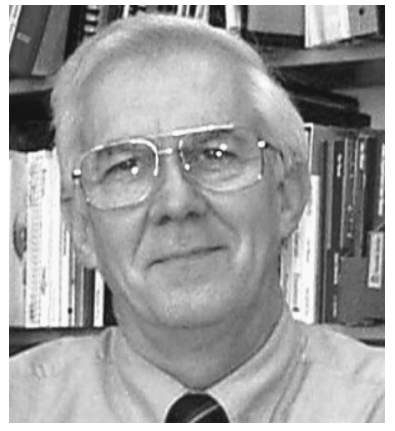

\section{The Optics Evangelist}

Although the economy in the United States and elsewhere may be in a downturn, you couldn't tell it from the demand for people trained in optics. Regularly I get calls and e-mails, some from former students, others from strangers, all asking for help in finding persons qualified in optics and optical engineering. I tell them that I'm sorry, but I can't help them. There are no optikers to be had. At least that I know of.

It is quite a contrast to a few years ago when my MS students were taking part-time jobs at places like Lockheed to keep body and soul together. As has been true in times past, when the job market wasn't promising for new optics grads, students were extending their education. It drove one of them into a $\mathrm{PhD}$ program. Since he's done well in this current drought, I don't feel nearly as bad as I did when my students were competing with more experienced optics professionals newly unemployed as a consequence of the aerospace downsizing. But that's all changed. You can't find anyone unemployed who knows that it does make a difference how you put a planoconvex lens in a laser beam and that a design based on the thin lens formula is a recipe for disaster.

So where are all the students?

Recently I happened to find a 1992 class roll for PHYS 3223, Geometrical Optics, in the back of a set of problems that I was revising for the current class. There were more than two dozen people in that class, most of whom went into optics. A number of them were taking it for master's credit. The current class has 9 students-only one or two of whom might be considered prospective optical engineers. It was disconcerting and depressing.

As for master's candidates, I haven't seen one in years. There is no support for students trained at the master's level because graduate program funds go only to $\mathrm{PhD}$ candidates.

In pondering this shortage, my first response was the standard Irish-Catholic one: blame yourself. What was I doing wrong? Where had I failed? Granted, Georgia Tech has never had a degree in optics, although it was contemplated at one time. Still, in the late seventies and eighties the Applied Physics program in the School of Physics did alright for itself, as my former students have told me. But, after I stopped blaming myself, I found that my program was not the only one suffering. The enrollment statistics from an aggregate of optics schools showed much the same decline over the decade of the nineties, but not quite as precipitous as mine.

One of the things we had going for us before 1990 was the novelty of the laser. A student had to get involved in optics to see real lasers and holograms. Now, the novelty is gone. People have laser pointers on their key chains and holograms on their credit cards. Optics and lasers, despite all of the attractions, are no longer the Latest Great Thing.

I think another thing has happened in the past decade. With the push to put computers in the classroom, there is a tendency to equate technology with computers. And among the student population there is some fraction with a technical or engineering bent. So, when these students reach college, what type of engineering or science will they be attracted to? The one that has "computer" in front of it.

For those out in the real world, the inability to hire men and women trained in optics must be frustrating. From what I understand from my friends in industry, most initiatives today are not limited by money, but by a lack of personnel. Some, in an effort to obtain technicians, are resorting to optics "boot camps," wherein recruits are given two weeks of intensive training and moved onto the factory floor. At Photonics West, several firms were recruiting students just beginning their optics training. Another source of optics professionals is retrained workers from the electronics and computer industry. Certainly SPIE is assisting by providing a slate of short courses that introduce photonics to those in electronics. Most recently, some telecommunications courses have been added with great success.

But most of these are holding actions. How and where are we going to get our next generation of optical engineers? It does no good to just wring our hands as we watch young people choose careers in computers. From all reports, students begin to narrow their career directions in late elementary and middle school. They are not easily reached, and having had a steady diet of TV and the media, they are not prone to hype from outside their own peer group. 
What we need is an Optics Evangelist who can preach the attractions of optics to all who will listen. He or she must be able to describe the satisfaction of putting together and proving a design, and point out that optics types do not sit in front of their computers all day; they can get up and make neat systems that never existed before. The Optics Evangelist must be able to provide this flock with information on how they, too, can become a much-sought-after optics person with a good salary and benefits.

But where are we to find this Optics Evangelist? Who is it that knows what it takes to train for the profession? Who can describe the types of challenges that face the optical engineer? And who can project the enthusiasm and satisfaction that is derived from their work in optics? The Optics Evangelist is any optical engineer who enjoys his or her profession.

No longer are you permitted to shrug off the question as to what you do. No longer can you permit people you meet to roll their eyes in their heads when they hear you are in optics. You need to gently remind them of the incredible optics technology they depend on every day. You need to hustle your kids and their friends, especially the tinkerers among them. Holograms, devices, stuff they have never seen before-all the gadgets that intrigue you-have to be collected and available for demonstration. To assist you, SPIE is marshalling an effort of local chapters and individuals to go into classrooms and demonstrate the wonders of optics. ${ }^{*}$ Whether you do a formal presentation such as these demonstrations or just a casual talk with a child or teenager, tell them what a great field we are lucky to work in. With the hundreds of careers that are available for students to choose from these days, it is up to us to assure that a stream of bright, interested students will be available to help us explore the great potential that optics offers society.

Donald C. O'Shea

Editor

*Additional information can be found on SPIE Web at http://spie.org/ CommunityServices/StudentsAndEducators/ 